\title{
Optimum early orthopaedic surgery in COVID-19 patients
}

Si Heng Sharon Tan, ${ }^{1}$ MMed, Choon Chiet $\underline{\text { Hong, }}{ }^{1}{ }_{F R C S}$, Soura Saha, ${ }^{1} M S c$, Hwee Weng Dennis $\underline{\text { Hey, }},{ }^{1}{ }_{F R C S}$, Diarmuid Murphy, ${ }^{1}{ }_{F R C S}$, James Hoipo Hui, ${ }^{1}{ }_{F R C S}$

Multiple guidelines have been established regarding the management of COVID-19 patients. ${ }^{1,2}$ However, there remains a paucity regarding specific guidelines on the optimal timing for surgeries in COVID-19 patients requiring early orthopaedic surgery. This paper aims to provide evidence-based recommendations regarding the timing to proceed with early orthopaedic surgeries in COVID-19 patients.

Haemodynamically unstable patients. In an unwell patient, the clinical urgency of the operation should be weighed against the overall health of the patient. A balance needs to be maintained between the benefits of early surgery and the possibility of worsening the patient's respiratory function from anaesthetic and surgical stresses. This is especially so as COVID-19 is a respiratory condition that can cause multi-organ dysfunction in symptomatic patients, significantly increasing the risk of the surgeries. Symptomatic patients under treatment for COVID-19 may also be on medications such as high-dose steroids and anticoagulants, which can significantly increase the risk of surgeries, necessitating the need to balance between the benefits of early surgery and the overall health of the patient. Haemodynamically unstable patients should undergo immediate surgery as soon as possible if the surgery may improve their condition, for example in unstable pelvic fractures, exsanguinating injuries, compartment syndrome or necrotising fasciitis. Other non-emergent surgeries should be postponed until the patient is stabilised.

Open fractures. The British Orthopaedic Association, British Association of Plastic Reconstructive and Aesthetic Surgeons, American College of Surgeons and Orthopaedic Trauma Association have released guidelines for open fracture management. ${ }^{3,4}$ Immediate surgical exploration for open fractures are recommended in the presence of gross contamination, compartment syndrome, vascular compromise and in a multiply injured patient, with full personal protective equipment (PPE) as soon as possible. ${ }^{3}$ In the absence of the above, initial debridement can be safely performed within 24 to 48 hours without adverse effects, once the patient's COVID-19 status is confirmed. ${ }^{3,4}$

Whenever possible, skin defects overlying open fractures should be closed during the initial debridement

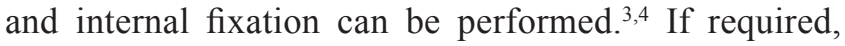
subsequent soft tissue reconstruction is recommended to be performed on day 7 before vessels become friable and fibrosed, with definitive internal fixation in the same setting. ${ }^{3,4}$ This is to maximise the duration for the treatment of COVID-19 while mitigating the risks of further delay.

Without soft tissue reconstruction, consideration should be given to definitive management of the fractures with external fixators. This is to decrease the risk of respiratory failure in COVID-19 patients during anaesthesia and intramedullary nailing of diaphyseal fractures, protect healthcare workers and conserve resources. Should subsequent skeletal stabilisation be required without soft tissue reconstruction, the surgery is recommended to be performed on day 14 to maximise the duration for the treatment of COVID-19 while mitigating the risks of further delay. ${ }^{3}$

Closed fractures and dislocations of extremities. Immediate surgical intervention with full PPE is recommended for closed fractures and dislocations with compartment syndrome or vascular compromise. This is to prevent irreversible muscle damage, with subsequent revascularisation possibly causing systematic complications including myoglobinuria, renal failure and death. The other indication for immediate intervention is that of a multiply injured patient who require other immediate surgery. However, this should be decided according to the surgical duration and the possibility of performing it after confirming or treating the COVID-19. ${ }^{5}$

Urgent surgeries are indicated for irreducible large joint dislocations. These include shoulder, elbow, hip, knee, ankle and subtalar dislocations. ${ }^{5-10}$ Whenever possible, joint dislocations should be reduced as soon as possible at bedside with full PPE. Failure of closed

\footnotetext{
${ }^{1}$ Department of Orthopaedic Surgery, National University Hospital, Singapore

Correspondence: Dr Tan Si Heng, Sharon, Department of Orthopaedic Surgery, National University Health System, 1E Kent Ridge Road, NUHS Tower Block Level 11, Singapore 119074.

Email: sharon_sh_tan@nuhs.edu.sg
} 
reduction then necessitates closed reduction under general anaesthesia or open reduction with full PPE. This is to avoid traction or compressive injuries to neurovascular structures. ${ }^{5-10}$

Early surgeries for closed fractures and dislocations are warranted in 6 scenarios. (1) Posterior sternoclavicular joint dislocations are recommended to be reduced within 48 to 72 hours as risk of failure of closed reduction increases beyond. ${ }^{11}$ (2) Floating elbows and knees are recommended to undergo early fixation to improve functional outcomes. ${ }^{12,13}$ (3) Closed fractures or dislocations with suspected nerve lacerations are recommended to have exploration and nerve repair early as Wallerian degeneration occurs within 24 to 48 hours. ${ }^{14}$ (4) Hip fractures are recommended to undergo surgery within 48 hours with a significant decrease in fatality and risk of pressure sores..$^{15}$ (5) Though controversial, if fixation is decided for proximal humerus fractures, early fixation can be performed as studies report a decreased rate of avascular necrosis when performed within 48 hours. ${ }^{16}$ Recent metaanalyses, however, identified that the timing of surgery has no bearing on the risks of avascular necrosis for young neck of femur fractures and talar neck fractures. Therefore, decision to proceed with early surgery is dependent on the consultant's practice. ${ }^{17,18}$ (6) Closed fractures and dislocations with skin tenting and impending conversion to open fractures are warranted early surgery as per open fractures.

Other closed fractures and dislocations are recommended to have their surgeries on day 14 if decision is made for surgical fixation. This is to maximise the duration for the treatment of COVID-19 while mitigating the risks of further delay. An exception is for acromioclavicular joint dislocations, where surgeries can be performed on day 21 and still be associated with good functional outcomes and reduction. ${ }^{19}$ Anterior sternoclavicular joint dislocations can also be left unreduced should closed reduction fails. ${ }^{5}$

Septic arthritis and periprosthetic joint infections. British Orthopaedic Association, British Society for Rheumatology, British Health Professionals in Rheumatology, Royal College of General Practitioners and British Society for Antimicrobial Chemotherapy published guidelines for septic arthritis. ${ }^{20}$ They recommended early removal of intra-articular pus followed by antibiotics. ${ }^{20}$ Options include repeated needle aspiration to dryness or surgical drainage done arthroscopically or open, with limited evidence to suggest one over another. ${ }^{20}$ In the setting of COVID-19 patients, bedside aspiration is therefore recommended as soon as possible with full PPE, and early surgical drainage could be performed after confirming the COVID-19 status if surgical drainage is the institution's practice.

The International Consensus on Orthopaedic Infections published guideline for periprosthetic joint infections. ${ }^{21}$ They recommended for surgery to be performed urgently once the patient is optimised, but not as an emergency. ${ }^{21}$ The exact cut-off time for surgery to be performed has not been established, but a shorter duration of symptoms is significantly correlated with higher success rates of surgery. Therefore surgery should be performed once the COVID-19 status of the patient is confirmed. ${ }^{21}$

Infected wounds or abscesses. Superficial infection can be managed with trial of medical therapy with close observation for progression to deep tissue infection. Deep tissue infections are, however, recommended early surgery to minimise the risk of ascending infection and compartment syndrome once the COVID-19 status of the patient is confirmed. These interventions may be required urgently in the presence of systemic toxicity.

Lacerations or deep abrasions. Newer studies and guidelines have demonstrated no relationship between the timing of surgery and infection risk up until 19 hours after injury. ${ }^{22}$ Wounds that require surgery should therefore be operated after confirming the COVID-19 status of the patients.

Tendon ruptures or muscle tears. The effect of the timing of tendon repair or muscle tears remain controversial. ${ }^{23}$ Two studies showed no difference in outcomes even if the surgery is delayed for 3 weeks, while the last study demonstrated a decrease in final active range of motion of 0.3 degree with each day of delay for flexor tendon repair. ${ }^{23}$ Accordingly, closed tendon ruptures or muscle tears should be operated after confirming the COVID-19 status, with the exact timing dependent on the consultant's practice. Patients with a wound overlying the tendon rupture or muscle tear should have early surgery as per the recommendations for lacerations and deep abrasions.

Locked joints. Locked joints are advised to have early surgeries to minimise stiffness and limited range of motion. However, there is limited evidence regarding the exact timing for these surgeries. The surgeries should be done after confirming the COVID-19 status, though the exact timing can be decided by the consultant in view of the controversial evidence.

Spinal trauma, cord compression or cauda equina. There is agreement that incomplete spinal cord injury may result in better neurological outcomes following early surgery, ideally within 6 hours. ${ }^{24}$ Patients with incomplete spinal cord injury or cauda equina should therefore have their surgery performed immediately with 
full PPE, or after confirmation of the COVID-19 status of the patient if possible within 6 hours.

In complete neurological deficit, however, some studies show no neurological improvement after early surgery, though surgery within 72 hours had lower risk of complications and length of stay. ${ }^{25}$ Therefore, patients with complete neurological deficit or no neurological deficits can have their surgery after confirming the COVID-19 status, with close neurological monitoring to ascertain if there is worsening neurology.

Patients with central cord syndrome, without any fractures or dislocations rendering the cervical spine unstable, generally have better prognosis. ${ }^{26}$ In the absence of evolving neurological deficits, they can have surgery after confirming the COVID-19 status as deemed appropriate by the consultant.

In the event of haemodynamic instability due to neurogenic shock, the optimal timing of surgery is as per recommended for other haemodynamically unwell patients.
Elective surgeries. Elective surgeries, except for oncological surgeries, should be postponed in the face of the pandemic. Oncological surgeries should be performed after confirmation of COVID-19 status, and if possible, after treatment of COVID-19. If any of the patients scheduled for other elective surgeries become a suspected or confirmed COVID-19 patient, the operation should be postponed until treatment is completed.

Evidence-based recommendations regarding the timing to proceed with early orthopaedic surgeries in COVID-19 patients are summarised in Table 1. These are made based on 3 main principles. Firstly, when faced with an unwell patient, saving lives takes precedence over saving limbs. Secondly, in a well patient, the clinical urgency of the operation should be weighed against the possibility of delaying the operation until the infectivity of the patient's COVID-19 is eliminated or lowered, or at least until the COVID-19 status of the patient is known. Lastly, elective surgeries, except for oncological surgeries, should be postponed during the pandemic.

Table 1. Summary of recommendations for the optimal timing for early orthopaedic surgeries in COVID-19 patients

\begin{tabular}{|c|c|}
\hline Condition & Recommendation \\
\hline \multicolumn{2}{|l|}{ Haemodynamically Unstable Patients } \\
\hline Unstable pelvic fractures & Immediate surgery \\
\hline Exsanguinating injuries & Immediate surgery \\
\hline Compartment syndrome & Immediate surgery \\
\hline Necrotising fasciitis & Immediate surgery \\
\hline Other conditions & Postponed until the patient is stabilised \\
\hline \multicolumn{2}{|l|}{ Open Fractures } \\
\hline Gross contamination & Immediate surgery \\
\hline Compartment syndrome & Immediate surgery \\
\hline $\begin{array}{l}\text { Initial debridement of open fractures without gross contamination, } \\
\text { compartment syndrome or vascular compromise }\end{array}$ & Within 24 to 48 hours $^{\mathrm{a}}$ \\
\hline $\begin{array}{l}\text { Subsequent soft tissue reconstruction with definitive skeletal } \\
\text { stabilisation }\end{array}$ & 7 days following injury ${ }^{\mathrm{b}}$ \\
\hline Skeletal stabilisation without soft tissue reconstruction & 14 days following injury if surgery is required ${ }^{b}$ \\
\hline \multicolumn{2}{|l|}{ Closed Fractures and Dislocations of Extremities } \\
\hline Impending conversion to open fractures & As per open fracture recommendations above \\
\hline Vascular compromise & Immediate surgery \\
\hline Multiply injured patient who require other immediate surgery & $\begin{array}{l}\text { Decided according to the surgical duration and the possibility of delaying } \\
\text { surgery }\end{array}$ \\
\hline
\end{tabular}


Table 1. Summary of recommendations for the optimal timing for early orthopaedic surgeries in COVID-19 patients (Cont'd)

\begin{tabular}{|c|c|}
\hline Condition & Recommendation \\
\hline Posterior sternoclavicular joint dislocations & Within 48 to 72 hours $^{\text {a }}$ \\
\hline Floating elbows and knees & Within 24 to 48 hours $^{\text {a }}$ \\
\hline Closed fractures with nerve lacerations & Within 24 to 48 hours $^{\mathrm{a}}$ \\
\hline Hip fractures & Within 48 hours $^{\mathrm{a}}$ \\
\hline Proximal humerus fixation & Within 48 hours $^{\mathrm{a}}$ \\
\hline Young neck of femur fractures & Dependent on consultant's decision ${ }^{\mathrm{a}} \mathrm{b}$ \\
\hline Talar neck fractures & Dependent on consultant's decision ${ }^{\mathrm{a}} \mathrm{b}$ \\
\hline Acromioclavicular joint dislocations & 21 days following injury ${ }^{\mathrm{b}}$ \\
\hline Anterior sternoclavicular joint dislocations & Leave unreduced should closed reduction fails \\
\hline \multicolumn{2}{|l|}{ Septic Arthritis and Periprosthetic Joint Infections } \\
\hline Septic arthritis bedside aspiration & As soon as possible \\
\hline Septic arthritis surgical drainage & After confirming COVID-19 status of patients \\
\hline Periprosthetic joint infections & After confirming COVID-19 status of patients \\
\hline \multicolumn{2}{|l|}{ Infected Wounds or Abscesses } \\
\hline Superficial infections & Managed with trial of medical therapy \\
\hline Deep tissue infections & After confirming COVID-19 status of patients \\
\hline \multicolumn{2}{|l|}{ Lacerations or Deep Abrasions } \\
\hline Lacerations or deep abrasions & After confirming COVID-19 status of patients \\
\hline Open tendon ruptures or muscle tears & As per lacerations or deep abrasions recommendations above \\
\hline Closed tendon ruptures or muscle tears & $\begin{array}{l}\text { After confirming COVID-19 status of patients, but exact timing dependent } \\
\text { on consultant's decision }\end{array}$ \\
\hline \multicolumn{2}{|l|}{ Locked Joints } \\
\hline Locked joints & $\begin{array}{l}\text { After confirming COVID-19 status of patients, but exact timing dependent on } \\
\text { consultant's decision }\end{array}$ \\
\hline \multicolumn{2}{|l|}{ Spinal Trauma, Cord Compression or Cauda Equina } \\
\hline Incomplete spinal cord injury & Within 6 hours $^{\mathrm{a}}$ \\
\hline Complete spinal cord injury & Within 72 hours $^{\mathrm{a}}$ \\
\hline Spinal trauma with no neurological deficit & After confirming COVID-19 status of patients \\
\hline Central cord syndrome without any fractures or dislocations & $\begin{array}{l}\text { After confirming COVID-19 status of patients if deemed appropriate by } \\
\text { the consultant }\end{array}$ \\
\hline Neurogenic shock & As per haemodynamically unstable recommendations above \\
\hline \multicolumn{2}{|l|}{ Elective Surgeries } \\
\hline Oncological procedures & $\begin{array}{l}\text { After confirming COVID-19 status of patients, and if possible, after treatment } \\
\text { of COVID-19 }\end{array}$ \\
\hline Other elective surgeries & Postponed in the face of pandemic \\
\hline
\end{tabular}

${ }^{a}$ Confirmation of COVID-19 status should be obtained during the timeframe if possible

${ }^{\mathrm{b}}$ Treatment should be started for COVID-19 positive patients during the timeframe if possible 


\section{REFERENCES}

1. Tan THY, Toh MPHS, Vasoo S, et al. Coronavirus Disease 2019 (COVID-19): The Singapore Experience. A Review of the First Eight Months. Ann Acad Med Singap 2020;49:764-78.

2. Chen JI, Yap JC, Hsu LY, et al. COVID-19 and Singapore: From Early Response to Circuit Breaker. Ann Acad Med Singap 2020; 49:561-72.

3. Nanchalal J, Nayagam S, Khan U, et al. Standards for the management of open fractures of the lower limb. British Association of Plastic Reconstructive and Aesthetic Surgeons 2009. 1st ed. Royal Society of Medicine Press Ltd; 2010.

4. Committee of Trauma, Orthopaedic Trauma Association. ACS TQIP best practices in the management of orthopaedic trauma, November 2015. Available at: https://www.facs.org/quality-programs/ trauma/tqp/center-programs/tqip/best-practice. Accessed on 7 January 2021.

5. Gutkowska O, Martynkiewicz J, Urban M, et al. Brachial plexus injury after shoulder dislocation: a literature review. Neurosurg Rev 2018;43:407-23.

6. Kellam P, Ostrum RF. Systematic review and meta-analysis of avascular necrosis and posttraumatic arthritis after traumatic hip dislocation. J Orthop Trauma 2016;30:10-6.

7. Richter DL, Bankhead CP, Wascher DC, et al. Knee Dislocation (KD) IV Injuries of the Knee: Presentation, treatment, and outcomes. Clin Sports Med 2019;38:247-60.

8. Wight L, Owen D, Goldbloom D, et al. Pure Ankle Dislocation: a systematic review of the literature and estimation of incidence. Injury 2017;48:2027-34.

9. Rammelt S, Bartoníček J, Park KH. Traumatic injury to the subtalar joint. Foot Ankle Clin 2018;23:353-74.

10. Vuillermin C, Donohue KS, Miller P, et al. Incarcerated medial epicondyle fractures with elbow dislocation: risk factors associated with morbidity. J Pediatr Orthop 2019;39:e647-51.

11. Sernandez H, Riehl J. Sternoclavicular joint dislocation: a systematic review and meta-analysis. J Orthop Trauma 2019; 33:e251-5

12. Vallier HA, Manzano GW. Management of the floating knee: Ipsilateral fractures of the femur and tibia. J Am Acad Orthop Surg 2020;28:e47-54

13. Yokoyama K, Itoman M, Kobayashi A, et al. Functional outcomes of "floating elbow" injuries in adult patients. J Orthop Trauma 1998; 12:284-90.
14. Griffin JW, Hogan MV, Chhabra AB, et al. Peripheral nerve repair and reconstruction. J Bone Joint Surg Am 2013;95:2144-51.

15. Moja L, Piatti A, Pecoraro V, et al. Timing matters in hip fracture surgery: patients operated within 48 hours have better outcome: a meta-analysis and meta-regression of over 190,000 patients. PLoS One 2012;7:e46175.

16. Schnetzke M, Bockmeyer J, Loew M, et al. Rate of avascular necrosis after fracture dislocations of the proximal humerus: timing of surgery. Obere Extrem 2018;13:273-8.

17. Halvorson JJ, Winter SB, Teasdall RD, et al. Talar neck fractures: a systematic review of the literature. J Foot Ankle Surg 2013; 52:56-61.

18. Damany DS, Parker MJ, Chojnowski A. Complications after intracapsular hip fractures in young adults: a meta-analysis of 18 published studies involving 564 fractures. Injury 2005;36:131-41.

19. Song T, Yan X, Ye T. Comparison of the outcome of early and delayed surgical treatment of complete acromioclavicular joint dislocation. Knee Surg Sports Traumatol Arthrosc 2016; 24:1943-50

20. Coakley G, Mathews C, Field M, et al. British Society for Rheumatology Standards, Guidelines and Audit Working Group. BSR \& BHPR, BOA, RCGP and BSAC Guidelines for management of the hot swollen joint in adults. Rheumatology (Oxford) 2006; 45:1039-41

21. Argenson JN, Arndt M, Babis G, et al. Hip and knee section, treatment, debridement and retention of implant: Proceedings of international consensus on orthopedic infections. J Arthroplasty 2019;34:S399-419.

22. Forsch RT, Little SH, Williams C. Laceration repair: A practical approach. Am Fam Physician 2017;95:628-36.

23. Hurley CM, Reilly F, Callaghan S, et al. Negative predictors of outcomes of flexor tendon repairs. Cureus 2019;11:e4303.

24. Fehlings MG, Rabin D, Sears W, et al. Current practice in the timing of surgical intervention in spinal cord injury. Spine (Phila Pa 1976) 2010;35:S166-73

25. McKinley W, Meade MA, Kirshblum S, et al. Outcomes of early surgical management versus late or no surgical intervention after acute spinal cord injury. Arch Phys Med Rehabil 2004;85:1818-25.

26. Anderson KK, Tetreault L, Shamji MF, et al. Optimal timing of surgical decompression for Acute Traumatic Central Cord Syndrome: a Systematic Review of the Literature. Neurosurgery 2015;77:S15-32. 